\title{
Selection of family members for communication of cancer risk and barriers to this communication before and after genetic cancer risk assessment
}

Deborah J. MacDonald, PhD, $R N^{1}$, Linda Sarna, DNSc, $R N^{2}$, Gwen van Servellen, $R N, P h D^{2}$, Roshan Bastani, $P h D^{3}$, Joyce Newman Giger, EdD, $R N^{2}$, and Jeffrey N. Weitzel, $M D^{1}$

\begin{abstract}
Purpose: The impact of genetic cancer risk assessment on communication of cancer risk information within families is not fully known. We compared women's selection of family members for cancer risk communication and perceived barriers to this communication before genetic cancer risk assessment and 6 months afterward. Methods: Mailed surveys were used to collect prospective data from consenting women undergoing genetic cancer risk assessment because of a personal and/or family history of breast or ovarian cancers. Analysis included descriptive statistics, chi-square and McNemar tests, and paired $t$ tests. Results: A total of 122 women met the study criteria. Although risk communications increased with first-degree relatives (84\%-90\% for females; $53 \%-$ $62 \%$ for males) and decreased with non-first-degree relatives (21\%-9\%) before and after genetic cancer risk assessment, the degree of change was nonsignificant. The most commonly cited communication barrier was loss of contact (30\%). Demographics, personal or family cancer history, and BRCA status did not significantly influence findings. Conclusions: There was a high degree of cancer risk communications with female first-degree relatives, but less so with male first-degree relatives, both before and after genetic cancer risk assessment. For the majority of women, interpersonal barriers did not preclude risk discussions. Further research is needed to identify how best to facilitate risk communication. Genet Med 2007:9(5):275-282.
\end{abstract}

Key Words: family communication, cancer risk communication, communication barriers, genetic counseling, breast cancer

In the United States, breast cancer is the most common cancer in women and is second only to lung cancer in cancerrelated deaths for women. ${ }^{1}$ Although ovarian cancer strikes far fewer women, the mortality rate is disproportionately higher, often because of insufficient early diagnostic tools. Risks for these cancers vary greatly. For instance, breast cancer risk for women with a single first-degree relative (FDR) with postmenopausal breast cancer may be $15 \%$ versus $12 \%$ risk for the general population by age 80 years. Ovarian cancer risk for a woman with a single FDR with the disease is approximately $5 \%$, versus the $1.6 \%$ risk for the general population..$^{2-5}$ However, breast cancer risk for women who carry a $B R C A$ gene mutation ranges from approximately $30 \%$ to $50 \%$ by age 50 years to as

\footnotetext{
From the ${ }^{I}$ Clinical Cancer Genetics Department, City of Hope Cancer Center, Duarte, California; ${ }^{2}$ School of Nursing, University of California, Los Angeles, California; ${ }^{3}$ School of Public Health, and Cancer Prevention and Control, Jonsson Comprehensive Cancer Center, University of California, Los Angeles, California.

Deborah J. MacDonald, PhD, RN, APNG, City of Hope Comprehensive Cancer Center, Clinical Cancer Genetics Dept., 1500 E. Duarte Rd., Duarte, CA 91010-3000. E-mail: dmacdonald@coh.org.
}

The authors declare no conflict of interest.

Submitted for publication September 15, 2006.

Accepted for publication February 16, 2007

DOI: 10.1097/GIM.0b013e31804ec075 high as $87 \%$ by age 80 years in some families, with a $40 \%$ to $60 \%$ risk for a second primary breast cancer. ${ }^{6-8}$ The associated risk for ovarian cancer is approximately $15 \%$ to $45 \%$, with onset generally after age 40 years rather than after age 60 years in the general population. $6,7,9$ Siblings and offspring of $B R C A$ mutation carriers are at a $50 \%$ risk for inheriting the mutation. Because men rarely develop breast cancer and are not at risk for ovarian cancer, $B R C A$-associated risk may be masked by male transmission and unrecognized by both clinicians and patients.

Since the advent of commercial BRCA testing approximately a decade ago, genetic cancer risk assessment (GCRA) has been increasingly integrated into women's health care to provide individuals and their families with age- and risk-level appropriate cancer screening and risk-reduction strategies. GCRA is typically conducted by a physician and nurse or genetic counselor team with expertise in genetics and/or oncology, with psychologists, social workers, ethicists, and legal consultants available as needed. ${ }^{10-12} \mathrm{~A}$ key component of GCRA is discussing the cancer risk implications for family members and encouraging the consultands to communicate this information to their relatives. ${ }^{13,14}$ In addition to fostering risk awareness, informing relatives could avoid potential ethical and legal dilemmas, because clinician duty to inform at-risk relatives of cancer risks is not yet fully clarified. ${ }^{15,16}$ Current opinion sug- 
gests that this obligation is satisfied by instructing patients to communicate risk information to family members. ${ }^{15}$

Informing relatives of cancer risk is often a key reason for seeking risk assessment and may motivate women to seek out relatives with whom they have had little contact (J. N. Weitzel and D. J. MacDonald, unpublished data, 2005). Clinician encouragement of intrafamilial risk communication may further facilitate this discourse, particularly when risk-reducing strategies are available. Although risk awareness is critical to cancer-control efforts, communicating cancer risk has emotional, psychologic, cultural-social, and behavioral implications. Anxiety about personal cancer risk, relatives' cancer risk, and guilt about passing the risk to children may be triggered by, or present barriers to, this communication. ${ }^{17,18}$ Risk communication may also adversely affect family relationships or dynamics. ${ }^{19-21}$ Despite potential health care benefits, some women may be reluctant or unwilling to discuss cancer risk with their relatives, fearing negative consequences or for other reasons, such as emotional or physical distance. ${ }^{22-25}$ Furthermore, not all women will believe that they have a duty to inform relatives of cancer risk, and some women may prefer their health care provider to convey this information. ${ }^{26}$

The majority of studies investigating family cancer risk communication have focused strictly on communication of $B R C A$ test results. These studies have found that women are concerned about relatives' cancer risks and share test results with at least one close family member, most often a female FDR, generally within a few weeks after results disclosure ${ }^{21-23,25,27-33}$. Women also discussed cancer risk information with their spouses, who may influence whether risk communications to children ensue and the nature of these discussions. ${ }^{20,27,34} \mathrm{Par}$ ticipants in most of these studies had free research-based BRCA testing 21,23,25,28-32 and/or were members of the same family, ${ }^{21,31,29}$ factors that may have enhanced the uptake of genetic testing and/or influenced family risk communications. Cancer risk assessment, however, is not simply a matter of genetic test results, and a negative result is simply uninformative with respect to estimating cancer risk in families without a previously identified causative mutation. Technologic limitations, a mutation in another gene, family history, and other factors must be taken into consideration for the $70 \%$ to $80 \%$ of patients who will receive recommendations based on a variety of empiric risk models, not a detectable gene mutation.

The current study was conducted to explore family communication of cancer risk by unrelated women before and by 6 months post-GCRA in fee-for-service high-risk clinics, regardless of whether $B R C A$ testing was performed, and factors affecting this communication. The study was part of a larger City of Hope Comprehensive Cancer Center Cancer Screening and Prevention Program Network ${ }^{\mathrm{SM}}$ (CSPPN) Institutional Review Board-approved study examining cancer risk-related health beliefs and behaviors. The research questions were as follows: (1) Are there differences in the type of family member selected for communication of cancer risk comparing the baseline with 6 months post-GCRA? (2) Are there differences in perceived barriers to this communication at the same time points? (3)
Are there differences in these two variables at the same time points by demographics, personal or family history of breast and/or ovarian cancers, or BRCA status? Because the importance of risk awareness for relatives is emphasized during GCRA, and because demographic characteristics, biological relationships, personal and family cancer history, and $B R C A$ status influence health communication in families, ${ }^{35-38}$ including genetic cancer risk communication, ${ }^{33,34}$ we hypothesized that GCRA and these factors would influence the type and number of relatives selected for cancer risk communication and the type and number of perceived communication barriers in our sample.

\section{MATERIALS AND METHODS}

\section{Design}

The larger prospective comparative study design has been reported. ${ }^{39}$ In brief, data were collected using self-administered surveys mailed in consecutive order as women scheduled their GCRA appointment and again at 1 month and 6 months post-GCRA. The current study used a longitudinal comparative design with two measurement intervals: before GCRA and by 6 months post-GCRA. For the purpose of this study, family history was defined as having at least one first-, second-, or third-degree blood relative diagnosed with a breast or ovarian cancer; cancer history was defined as a personal or family history of breast and/or ovarian cancers, and stage and histology of these cancers for the cancer history group; and BRCA status was defined as tested or not tested and mutation positive or no mutation identified. Health status encompassed both cancer history and $B R C A$ status.

\section{Eligibility}

Eligibility for the parent study consisted of being a woman with a personal and/or family history of breast or ovarian cancers who was referred for GCRA at the CSPPN cancer center clinic in Los Angeles County, Orange County, or Santa Barbara County ${ }^{39}$ and consented to participate before being seen for GCRA $(n=224)$. The clinics serve a predominately white (75\%) insurance-covered population. The current study sample consisted of women accrued to the parent study who responded to at least one survey item assessing cancer risk communications with family members and perceived barrier to this communication before and by 6 months post-GCRA.

\section{Sample and setting}

Of the 224 potentially eligible women, post-GCRA data were missing for 9 (4\%) because 7 never presented for GCRA and 2 died shortly after GCRA. Of the remaining 215 women, 135 (63\%) responded to the item assessing risk communication pre- and post-GCRA. Responses to the perceived barriers item were reported by 122 women (90\% of the 135 discussants) at both time points. Demographics and cancer histories were similar to nonparticipating study-eligible women, to women in the parent study who did not meet eligibility for this study, and to the underlying CSPPN clinic population. ${ }^{39}$ 


\section{Procedures/measures}

Data were previously collected between August 1999 and December 2001 from standard self-administrated health and family history surveys and medical records. The study survey was mailed to women before their initial GCRA appointment (225/543 responded [41\%]) and again at 1 month and 6 months post-GCRA. ${ }^{39}$ Participants in the parent study were similar in demographics to the same number of nonparticipating study-eligible women with and without a personal and/or family history of breast or ovarian cancers.

Family pedigrees were examined to determine (1) whether it was possible for a woman to communicate to a particular family member (i.e., if each woman had a living mother, father, and so forth) and (2) age of children/siblings. Although we wanted to capture the full range of communication, it was reasonable to expect that women would not discuss cancer risk with relatives younger than school age, defined as less than 6 years of age.

\section{Risk-communication measures}

Cancer risk communication was measured by responses of "no," "yes," or "N/A" (not applicable) to "Have you discussed cancer risk with family members?" The seven response options were spouse/partner and all FDRs, that is, mother, sister(s), daughter(s), father, brother(s), and son(s). Communication barriers were measured by responses of "yes" or "no" to "Have any of the following prevented you from discussing cancer risk with one or more family members?" The eight response options were "concern about upsetting relatives," "recalling painful memories," "difficult family relationships," "hard to talk about cancer risk," "age differences," "relatives live too far away," "lost touch with some relatives," and "information not useful to relatives." An "Other (specify)" category was provided for both items for write-in responses.

\section{Instrument validity and reliability}

The survey items described above were developed from the literature including the work of Lerman et al., ${ }^{27,28,40-42}$ and pilot testing with 50 study-eligible women, of whom 10 participated in an in-depth interview. ${ }^{27}$ Survey items assessing cancer history and clinical characteristics were developed according to national health care guidelines (e.g., the American Cancer Society). ${ }^{43}$ Content validity of the survey, including the communication items, was established by an expert genetic/ oncology judge panel (three nurse researchers, a physician, and a clinical research associate) who evaluated each item as it related to the content domain until $100 \%$ item agreement was obtained. ${ }^{39}$ The survey was reviewed for content, readability, and clarity by a judge panel of five women (three non-health care professionals employed at City of Hope, an educator, and an expert hereditary cancer risk counselor nurse in the midwest). Revisions incorporating participant/reviewer comments were made before use in the parent study. Reliability of responses to communication with relatives is implied in that there was not a statistically significant change in the reported type of relative women with whom cancer risk was discussed, or reported communication barriers, at the two time points. Demographic characteristics, health status, and information about family structure were previously confirmed by review of survey responses during GCRA and, when possible, by medical or other records.

\section{Data analysis}

Descriptive statistics (frequencies, percentages, mean, range, and standard deviation [SD]), Student $t$ test, and $\chi^{2}$ statistic were used to summarize the sample and outcome measures. McNemar tests were used to measure differences in the type of family member (e.g., sister) selected before and by 6 months post-GCRA. In addition, paired $t$ tests were conducted using a composite communication score created to represent the ratio of the total type of family member with whom a participant discussed cancer risk over the types possible (e.g., if a woman communicated with three of six types of family members in her family, this was scored as 0.50). Similar statistical tests were conducted to measure differences in each of the perceived communication barrier items, to create a communication barrier score representing the ratio of the total number of barriers reported over the eight barrier options, and to measure differences in selection of family members and communication barriers by demographics, personal history of breast and/or ovarian cancers, family history of these cancers, and $B R C A$ status. All tests were two-sided, using 0.80 power with significance set at a $P$ value of .006 (Bonferroni correction to account for multiple comparisons across the three outcome variables). Data were analyzed with the Statistical Package for the Social Sciences version 11.5 (SPSS Inc., Chicago, IL).

\section{RESULTS}

The demographic characteristics, cancer history, BRCA status, family members at least 6 years of age who were selected for cancer risk communication, and perceived barriers to this communication pre- and post-GCRA are depicted in Tables 1 to 4 .

\section{Sample characteristics}

Demographic characteristics of the sample as a whole and subdivided by personal and family cancer history are displayed in Tables 1 and 2. The majority of the women were between ages 40 and 60 years, white, married, college graduates, Christian, and had children. Approximately two thirds (62\%) of the women had at least one living child aged 18 years or more ( $64 \%$ were daughters and $60 \%$ were sons), $81 \%$ had at least one child aged between 13 and 17 years ( $86 \%$ were daughters; $77 \%$ were sons), and $20 \%$ had a child aged between 6 and 12 years (7\% were daughters, $13 \%$ were sons). Respondents and nonrespondents were similar in demographics (age, ethnicity/race, education, marital status, children, and religion) and personal/ family history of breast or ovarian cancers. The sample is representative of the underlying high-risk clinic population's demographics/cancer history and appears to be comparable to 
Table 1

Demographic characteristics and cancer history of sample

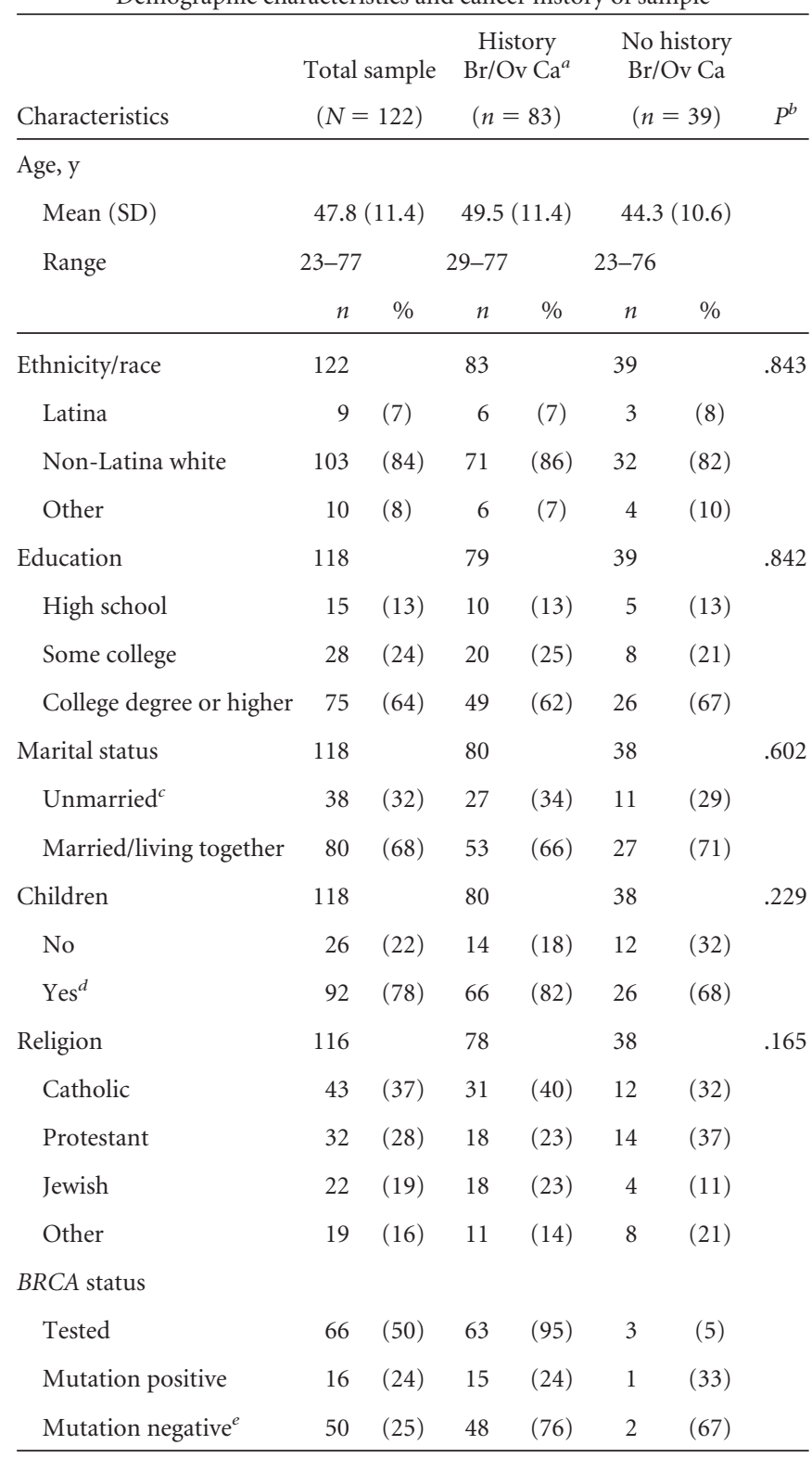

$\mathrm{SD}$, standard deviation; $\mathrm{Br} / \mathrm{Ov} \mathrm{Ca}$, breast and/or ovarian cancers.

Percentage reflects available data.

${ }^{a}$ Personal history of breast and/or ovarian cancers.

${ }^{b} P$ values refer to comparison of distribution of frequencies between the history and no history groups.

${ }^{c}$ Single, divorced, separated, widowed.

${ }^{d}$ Range in age: $6-59$ years; $62 \%$ of the sample had at least one child aged $\geq 18$ years.

${ }^{e}$ Negative $=$ no deleterious mutation; no variants of uncertain significance were identified.

other reported studies of a similar nature. There were no significant group differences in demographics (Table 1).

Sixty-nine $(83 \%)$ of the 83 cancer survivors had a family history of breast or ovarian cancer (five cancer survivors had a family history of both cancers; Table 2). Only 3 (8\%) of the 39 women in the no cancer history group had a family history of ovarian but not breast cancers.
Table 2

Family cancer history of sample

\begin{tabular}{|c|c|c|c|c|c|c|}
\hline \multirow{2}{*}{$\begin{array}{l}\text { Family cancer } \\
\text { history }^{a}\end{array}$} & \multicolumn{2}{|c|}{$\begin{array}{c}\text { Total } \\
\text { sample } \\
(N=122)\end{array}$} & \multicolumn{2}{|c|}{$\begin{array}{c}\text { History } \\
\mathrm{Br} / \mathrm{Ov} \mathrm{Ca} \\
(n=83)\end{array}$} & \multicolumn{2}{|c|}{$\begin{array}{c}\text { No history } \\
\mathrm{Br} / \mathrm{Ov} \mathrm{Ca} \\
(n=39)\end{array}$} \\
\hline & $n$ & $\%$ & $n$ & $\%$ & $n$ & $\%$ \\
\hline & $121^{b}$ & & 69 & & 39 & \\
\hline Breast & 92 & (76) & 56 & (67) & 36 & (92) \\
\hline Ovarian & 22 & (18) & 13 & (16) & 15 & (39) \\
\hline No breast or ovarian & 16 & (13) & 16 & (13) & 0 & \\
\hline
\end{tabular}

$\mathrm{Br} / \mathrm{Ov} \mathrm{Ca}$, breast and/or ovarian cancers.

${ }^{a}$ Family history of breast and/or ovarian cancers.

${ }^{b}$ One woman adopted, family history unknown.

Table 3

Characteristics of women with breast cancer history $(N=78)$

Age at diagnosis, $\mathrm{y}$

Mean (SD)

$45.4(10.8)$

Range

$25-72$

\begin{tabular}{lcc}
\cline { 2 - 3 } & $N$ & $\%$ \\
\hline Cancer stage & 63 & $(18)$ \\
0 & 11 & $(32)$ \\
I & 20 & $(37)$ \\
II & 23 & $(11)$ \\
III & 7 & $(3)$ \\
IV & 2 & $(2)$ \\
Bilateral breast cancer & 2 & \\
Tumor histology & 68 & $(16)$ \\
DCIS & 11 & $(69)$ \\
Invasive ductal & 47 & $(9)$ \\
Invasive lobular & 6 & $(3)$ \\
Medullary & 2 & $(3)$ \\
Inflammatory & 2 &
\end{tabular}

DCIS, ductal carcinoma in situ; SD, standard deviation.

Sixty-six women (54\%) had a personal or family history suggestive of hereditary breast cancer or, in some cases, breast/ ovarian cancers (per standard criteria ${ }^{44}$ ). Of these, 50 had full sequencing of both $B R C A$ genes and 16 Ashkenazi Jewish women had testing for the three founder mutations responsible for approximately $95 \%$ of $B R C A$-related breast/ovarian cancers in Ashkenazim. Sixteen women (24.2\%) were found to carry a deleterious $B R C A$ mutation, including two Jewish cancer survivors and one of the three women without a personal cancer history.

Breast cancer characteristics are displayed in Table 3. Eighty-three women $(68 \%)$ had a personal history of breast cancer $(n=78 ; 63.9 \%)$ or ovarian cancer $(n=5 ; 4.1 \%$, mean age at diagnosis, 50 years; range, $38-72$ years; one stage I, four stage III). 
Table 4

Family member selected for cancer risk communication

\begin{tabular}{lcccc}
\hline $\begin{array}{l}\text { Sample } \\
(N=122)\end{array}$ & $\begin{array}{c}\text { Total No. of } \\
\text { relatives }^{a}\end{array}$ & $\begin{array}{c}\text { Pre-GCRA } \\
n(\%)\end{array}$ & $\begin{array}{c}\text { Post-GCRA } \\
n(\%)\end{array}$ & $P$ \\
\hline Female relatives & & & & \\
$\quad$ Sister(s) & 84 & $74(88)$ & $79(94)$ & .180 \\
$\quad$ Daughter(s) & 59 & $48(81)$ & $51(86)$ & .250 \\
$\quad$ Mother & 55 & $46(84)$ & $50(91)$ & .219 \\
Male relatives & & & & \\
Brother(s) & 77 & $41(53)$ & $47(61)$ & .238 \\
$\quad$ Son(s) & 63 & $32(51)$ & $41(65)$ & .064 \\
$\quad$ Father & 54 & $30(56)$ & $33(61)$ & .629 \\
Other relatives ${ }^{b}$ & - & $26(22)$ & $11(9)$ & $.009^{c}$ \\
Partner/spouse & 92 & $78(85)$ & $80(87)$ & .815 \\
\hline
\end{tabular}

${ }^{a}$ Age $\geq 6$ years.

${ }^{b}$ Primarily aunts and cousins.

'Nonsignificant; $P$ set at .006, Bonferroni correction for multiple comparisons.

\section{Cancer risk communications}

Cancer risk communications increased with all types of FDRs pre- to post-GCRA, but the degree of change was nonsignificant (Table 4). Most women (91\%) discussed cancer risk with female FDRs and their spouse/partner (86\%), whereas only $62 \%$ did so with male FDRs and far fewer indicated doing so with other relatives (primarily reported as aunts or cousins). The composite communication score did not significantly differ pre- $($ mean $=0.613, \mathrm{SD}=0.27)$ to post-GCRA $($ mean $=$ $0.646, \mathrm{SD}=0.21$; paired $t$ test, $t(121)=1.34, P=.18)$.

Changes in all of the communication barriers were reported pre- to post-GCRA, but the degree of change was again nonsignificant (Table 5). Some women (5\%-32\%) reported preand post-GCRA cancer risk communication barriers, mainly geographic distance, loss of contact, and difficult family relationships. Most women indicated at both time points that discussing cancer risk provided useful information to their rela-

Table 5

Barriers to cancer risk communication

\begin{tabular}{lcccc}
\hline Sample $(N=122)$ & $\mathrm{N}^{a}$ & $\begin{array}{c}\text { Pre-GCRA } \\
n(\%)\end{array}$ & $\begin{array}{c}\text { Pre-GCRA } \\
n(\%)\end{array}$ & $P$ \\
\hline Concern about upsetting others & 117 & $19(16)$ & $14(12)$ & .359 \\
Recalling painful memories & 116 & $18(15)$ & $11(9)$ & .118 \\
Geographic distance & 116 & $22(19)$ & $33(28)$ & .054 \\
Information not useful & 107 & $8(8)$ & $5(5)$ & .508 \\
Difficult family relationships & 117 & $10(9)$ & $15(16)$ & $.049^{b}$ \\
Difficulty talking about cancer risk & 117 & $15(13)$ & $7(6)$ & .077 \\
Age differences & 117 & $15(13)$ & $11(9)$ & .503 \\
Lost touch with relatives & 118 & $35(30)$ & $38(32)$ & .735 \\
\hline
\end{tabular}

${ }^{a}$ Respondents.

${ }^{b}$ Nonsignificant; $P$ set at .006, Bonferroni correction for multiple comparisons. tives and that difficulty talking about cancer risk did not prevent these discussions. The composite communication barrier score did not significantly differ pre- $($ mean $=1.35, \mathrm{SD}=$ 0.1 .61 ) to post-GCRA (mean $=1.21, \mathrm{SD}=1.40$; paired $t$ test, $t(121)=.934, P=.352)$. Risk communications were not significantly influenced by demographics, cancer history, $B R C A$ status, or GCRA (data not shown).

\section{DISCUSSION}

To the best of our knowledge, this is the first published study since the availability of commercial $B R C A$ testing to examine communication practices and barriers before and after risk assessment and counseling. The only study identified that assessed family communication of cancer risk at both time points was conducted a decade ago in the United Kingdom before commercial BRCA testing. ${ }^{32}$ In that study, most of the $46 \mathrm{fe}-$ male participants undergoing testing in the United Kingdom contacted at least one relative before and after genetic counseling.

The present study sample is similar in demographics (age, ethnicity/race, education, marital status, children, and religion) and personal/family history of breast or ovarian cancers, for both respondents and nonrespondents. The sample is representative of the underlying high-risk clinic population's demographics/cancer history and appears to be comparable to other reported studies of a similar nature. Despite the lack of statistically significant support for our hypotheses that intrafamilial cancer risk communications and communication barriers would be influenced by GCRA and other factors (demographic characteristics, biological relationships, personal and family cancer history, and BRCA status), we believe that several findings may have clinical relevance and provide further support for similar observations in the nascent literature. Further, we believe that the lack of statistical significance may be attributable to insufficient sensitivity of the two measurement items.

We began with testable hypotheses, but the exploratory nature of the study required multiple comparisons and the consequent need for a more stringent $P$ value (Bonferroni correction, 0.006). Therefore, statistically significant findings may have been obscured by lack of power to detect true differences. Findings of probable clinical relevance are that female relatives were informed about cancer risk more often than male relatives, and that although various psychosocial barriers to intrafamilial risk communication exist, for the majority of women these barriers do not preclude risk discussions.

\section{Cancer risk communication and communication barriers}

On average, women discussed cancer risk with three types of family members, both before and by 6 months after their final clinic visit. Consistent with our previous pilot study ${ }^{27}$ and other studies of postcounseling risk communication, the majority discussed risk with spouse/partners and female FDRs, particularly sisters, and fewer did so with male FDRs. ${ }^{23,24,31-33,45}$ Given the health care implications for the daughters of male FDRs in particular, further exploration to determine why males are not 
informed more often and how to support risk discussion with male relatives is warranted.

It is interesting that there was not a significant difference in communication or communication barriers by personal cancer history, because women treated for cancer might have a heightened concern about risk for their relatives; on the other hand, unaffected women's fears because of exposure to cancer in a close relative may have driven these discussions. For female relatives, a "ceiling effect" resulting from the overall high communication rate among these relatives may account for the inability to detect a difference. Although our pilot study findings suggested that women affected with breast cancer were more likely to communicate risk, ${ }^{27}$ other studies exploring dissemination of BRCA test results did not report a difference.

Personal cancer history did not make a difference in which relatives were told of the results for 273 women mailed a survey at 4 months after disclosure of the results. ${ }^{33}$ A study of 42 mothers indicated that regardless of cancer history or mutation status, mothers shared their BRCA test result with $53 \%$ of their 68 children ages 8 to 17 years within 1 month after learning the result. ${ }^{30}$ Carrier status or cancer history was not associated with $B R C A$ results disclosure in another mailed survey study of 109 mothers and 24 fathers from high-risk breast cancer families with one or more children aged less than 18 years. ${ }^{29}$ By 1 month after learning their test result, approximately $47 \%$ of the parents told the result to at least one child, regardless of whether the child was aged 13 years or younger or 14 to 18 years (exact ages were not collected). In our present study, most $(86 \%)$ of the women discussed cancer risk with at least one daughter, and fewer (65\%) did so with sons; the exact ages of the children are not known. Because approximately $38 \%$ of the women did not have a child aged 18 years or more, perhaps the discussions were meant to be reassuring and/or prepare the child for possible cancer risk in the future. ${ }^{35-38}$ Future studies could provide insight into the motivations and content of risk communications with younger children.

No published studies were identified that examined the influence of disease stage or histologic characteristics on cancer risk communications. In our study, the power to detect a difference by these characteristics pre/post-GCRA may have been limited given the few women with documented late stage ( $n=$ $9 ; 14.3 \%)$ or more histologically aggressive ( $n=8$ [four breast and four ovarian]; 11.0\%) malignancies. Investigating the influence of stage or histology on risk communication may be important because there is greater information content from testing affected individuals, and if women with late stage disease do not disseminate risk information, an opportunity to increase risk awareness among their relatives may be lost.

Although the direction of change is not stated in the hypothesis, we expected that barriers, especially those of an interpersonal nature, might be decreased after GCRA wherein the importance of communication is emphasized. However, we did not see a significant change in any of the assessed barriers. More than $90 \%$ of the women in our sample indicated that they thought the information learned during GCRA would be useful for their relatives. Yet this was not reflected in post-
GCRA communications, particularly with male relatives, or with relatives outside the nuclear family. However, on careful scrutiny of risk status, approximately half of the women did not have a personal or family history suggestive of single-gene hereditary cancer risk, and most women who tested negative for hereditary cancer risk were deemed to have had sporadic (multifactorial) disease. Perhaps these women thought that the assessed risk level was not worthy of additional discussion, particularly with relatives with whom they had lost contact or had challenging relationships.

When we looked at the barriers by BRCA status (tested/not tested, mutation positive/no mutation), each item showed the same trend in direction (increased). Thus it appears that in our sample $B R C A$ status did not influence women to overcome difficult family relationships to inform relatives of cancer risk. Difficult family relationships and other barriers of an interpersonal nature explored herein (Table 5) have been cited as preventing cancer risk discussions after genetic testing in several studies, ${ }^{22,23,27,32-34}$ including our pilot study. ${ }^{27}$ Again, this may be attributable to a ceiling effect among female relatives, but given the implications discussed during GCRA for daughters of male relatives, regardless of the test result, this finding was surprising.

Others have found that the outcome of $B R C A$ testing influenced results disclosure. In the aforementioned study of 273 women, who had free or subsidized research-based BRCA testing within several months of our study's timeframe, ${ }^{33}$ the outcome predicted which relatives were informed of the result, as did women's age. Conclusive results were shared more often than inconclusive results, women aged more than 40 years less often informed their parents, and results were disclosed to women more frequently than to males. An earlier study of 163 adult men and women ${ }^{31}$ also found that females were informed of the results more often than males, even within the same family. Another clinic-based study of women's communication of test results to their partners $(n=118)$ reported that most partners were informed of the result. ${ }^{46}$ These studies included only persons who had BRCA testing and did not assess precounseling communications, informing beyond FDRs, or reasons for nondisclosure.

\section{Facilitating risk discussions}

Women seen for GCRA are often motivated by concerns about cancer risks for their children and other family members. ${ }^{27,40,47}$ After GCRA, these women may be even more compelled to contact relatives with whom they have lost touch to share this information; some do so at gatherings such as a family reunion (J. N. Weitzel and D. J. MacDonald, unpublished data, 2005). Clinicians play a valuable role in facilitating these discussions by establishing a supportive clinician-provider relationship while emphasizing to patients the importance of informing relatives of the health care implications. They may emphasize the equal likelihood of transmitting breast/ovarian cancer risk factors (single gene and multifactorial) to offspring through either the paternal or maternal lineages and address potential barriers for women attempting to 
discuss risk for these cancers with male relatives (e.g., the perception that men will be less interested or less inclined to use the information for health care decisions; discomfort with discussing these issues with men). Other factors that may influence family communication (e.g., family communication style, role expectations, attitudes and beliefs, and experience with the health care system) are beyond the scope of this article but are reasonable targets for future research.

\section{Limitations}

There are several study limitations. Accurate determination of communication with relatives may have been hindered by the study design. That is, the number of relatives women actually communicated with compared with those they could have communicated with is unknown for other than parents, as is the nature and outcome of these discussions. In addition, communication with relatives outside the nuclear family was assessed by write-in response rather than checkbox. A construct wherein the respondent was required to actively indicate that communication occurred or did not occur with these relatives might have enabled us to capture communications more definitively. Thus, communication may have occurred with more relatives than was reported. Further, the high percentage of cancer survivors may have limited finding differences by cancer history. Also, the sample size may have been inadequate to detect significant differences. Future research with a larger sample may help to overcome this issue. Finally, as in most studies examining genetic cancer risk communication, our sample was composed of mainly non-Latino white, highly educated, married women with children, ${ }^{22-25,27,30,31,33,34,48,49}$ and as such, the findings may not be generalizable to underserved or ethnic minority populations. Nevertheless, this and published studies to date should be applicable to the high-risk population being seen in these clinics and thus are of practical merit.

\section{FUTURE DIRECTIONS}

Given the potential health care implications and the increasing use of genomic-based health care, additional research is needed to expand on our findings. Future research could explore how best to foster inter- and intrafamilial cancer risk communication with women who desire to do so, particularly with male relatives and those with whom they have lost contact or have challenging relationships, and assess the effects of this communication on family relationships and cancer screening and risk-reduction practices and outcomes.

\section{ACKNOWLEDGMENTS}

This research was supported by funds from the California Breast Cancer Research Program of the University of California, Grant Number 5BP-0051 (D. J. M.) and in part by funds received under a DSCN-03-199-03 Doctoral Scholarship in Cancer Nursing from the American Cancer Society (D. J. M.) and Grant Agreement No. 99-86874 with the California Department of Health Services, Cancer Research Section (J. N. W.).

\section{References}

1. Jemal A, Siegel R, Ward E, Murray T, et al. Cancer statistics, 2006. CA Cancer J Clin 2006;56(2):106-130.

2. Ziogas A, Gildea M, Cohen P, Bringman D, et al. Cancer risk estimates for family members of a population-based family registry for breast and ovarian cancer. Cancer Epidemiol Biomarkers Prev 2000;9 (1):103-111.

3. Narod SA, Olsson H. Risk of ovarian cancer in breast-cancer patients with a family history of either. Lancet 2003;361:(9352):179; author reply 179-180.

4. Claus EB, Risch N, Thompson WD. Autosomal dominant inheritance of early-onset breast cancer: implications for risk prediction. Cancer 1994;73:643-651.

5. NIH Consensus Conference. Ovarian cancer. Screening, treatment, and follow-up. NIH Consensus Development Panel on Ovarian Cancer. JAMA 1995;273:491-497.

6. Ford D, Easton DF, Stratton M, Narod S, et al. Genetic heterogeneity and penetrance analysis of the BRCA1 and BRCA2 genes in breast cancer families. The Breast Cancer Linkage Consortium. Am J Hum Genet 1998;62:676-689.

7. Struewing JP, Hartge P, Wacholder S, Baker SM, et al. The risk of cancer associated with specific mutations of BRCA1 and BRCA2 among Ashkenazi Jews. N Engl J Med 1997;336 (20):1401-1408.

8. Metcalfe K, Lynch HT, Ghadirian P, Tung N, et al. Contralateral breast cancer in BRCA1 and BRCA2 mutation carriers. J Clin Oncol 2004;22 (12):2328-2335.

9. Metcalfe KA, Lynch HT, Ghadirian P, Tung N, et al. The risk of ovarian cancer after breast cancer in BRCA1 and BRCA2 carriers. Gynecol Oncol 2005;96 (1):222-226.

10. Greco KE, Mahon SM. Genetics nursing practice enters a new era with credentialing. The Internet Journal of Advanced Nursing Practice 2003;5(2). Available at: http:// www.ispub.com/ostial/index.php?xmlFilePath=journals/jhan/front.xml. Accessed April 6, 2007.

11. International Society of Nurses in Genetics I. Statement on the scope and standards of genetics clinical nursing practice. Washington, DC: American Nurses Publishing, 1998.

12. MacDonald DJ, Sand S, Kass FC, Blazer KR, et al. The power of partnership: extending comprehensive cancer center expertise in clinical cancer genetics to breast care in community centers. Semin Breast Dis in press.

13. American Society of Human Genetics. Professional disclosure of familial genetics information. Am J Hum Genet 1998;62:474-483.

14. ASCO. American Society of Clinical Oncology policy statement update: genetic testing for cancer susceptibility. J Clin Oncol 2003;21:(12):2397-2406.

15. Offit K, Groeger E, Turner S, Wadsworth EA, et al. The "duty to warn" a patient's family members about hereditary disease risks. JAMA 2004;292 (12):1469-1473.

16. Keeling SL. Duty to warn of genetic harm in breach of patient confidentiality. J Law Med 2004;12 (2):235-253.

17. Lerman C, Croyle RT, Tercyak KP, Hamann H. Genetic testing: psychological aspects and implications. J Consult Clin Psychol 2002;70 (3):784-797.

18. MacDonald DJ. Ethical, legal, and social issues related to predisposition testing for breast cancer risk: what nurses need to know. Quality of Life-A Nursing Challenge 1997;6:8-14.

19. MacDonald DJ. Genetic predisposition testing for cancer: effects on families' lives. Holist Nurs Pract 1998;12 (3):9-19.

20. Kenen R, Arden-Jones A, Eeles R. We are talking, but are they listening? Communication patterns in families with a history of breast/ovarian cancer (HBOC). Psychooncology 2004;13 (5):335-345.

21. Sermijn E, Goelen G, Teugels E, Kaufman L, et al. The impact of proband mediated information dissemination in families with a BRCA1/2 gene mutation. J Med Genet 2004;41 (3):E23.

22. McGivern B, Everett J, Yager GG, Baumiller RC, et al. Family communication about positive BRCA1 and BRCA2 genetic test results. Genet Med 2004;6 (6):503-509.

23. Claes E, Evers-Kiebooms G, Boogaerts A, Decruyenaere M, et al. Communication with close and distant relatives in the context of genetic testing for hereditary breast and ovarian cancer in cancer patients. Am J Med Genet A 2003;116 (1):11-19.

24. Costalas JW, Itzen M, Malick J, Babb JS, et al. Communication of BRCA1 and BRCA2 results to at-risk relatives: a cancer risk assessment program's experience. Am J Med Genet 2003;119C (1):11-18.

25. Hughes C, Lerman C, Schwartz M, Peshkin BN, et al. All in the family: evaluation of the process and content of sisters' communication about BRCA1 and BRCA2 genetic test results. Am J Med Genet 2002;107 (2):143-150.

26. Miesfeldt S, Cohn WF, Jones SM, Ropka ME, et al. Breast cancer survivors' attitudes about communication of breast cancer risk to their children. Am J Med Genet $C$ Semin Med Genet 2003;119(1):45-50.

27. MacDonald DJ, Choi J, Ferrell B, Sand S, et al. Concerns of women presenting to a comprehensive cancer center for genetic cancer risk assessment. J Med Genet 2002; 39:526-530.

28. Lerman C, Croyle RT. Emotional and behavioral responses to genetic testing to cancer. Oncology 1996;19:191-199.

29. Tercyak KP, Hughes C, Main D, Snyder C, et al. Parental communication of BRCA1/2 genetic test results to children. Patient Educ Couns 2001;42:213-224. 
30. Tercyak K, Peshkin B, DeMarco T, Brogan B, et al. Parent-child factors and their effect on communicating BRCA1/2 test results to children. Patient Educ Couns 2002; 47(2):145.

31. Hughes C, Lynch H, Durham C, Snyder C, et al. Communication of BRCA1/2 test results in hereditary breast cancer families. Canc Res Ther Contr 1999;8:51-59.

32. Green J, Richards M, Murton F, Statham H, et al. Family communication and genetic counseling: the case of hereditary breast and ovarian cancer. J Genet Couns 1997;6:45-60.

33. Patenaude AF, Dorval M, DiGianni LS, Schneider KA, et al. Sharing BRCA1/2 test results with first-degree relatives: factors predicting who women tell. J Clin Oncol 2006;24(4):700-706.

34. Forrest K, Simpson SA, Wilson BJ, van Teijlingen ER, et al. To tell or not to tell: barriers and facilitators in family communication about genetic risk. Clin Genet 2003;64(4):317-326.

35. Bastani R, Maxwell AE, Bradford C, Das IP, et al. Tailored risk notification for women with a family history of breast cancer. Prev Med 1999;29(5):355-364.

36. Giger J, Davidhizar R. Transcultural nursing: Assessment \& intervention, 4th ed. St. Louis, MO: Mosby, 2004.

37. Loveland-Cherry CJ, Bomar PJ. Family health promotion and health protection. In: Bomar PJ, editors. Promoting health in families applying family research and theory to nursing practice, Vol. 3. Philadelphia: Saunders, 2004;61-89.

38. Sarna L, Tae YS, Kim YH, Brecht ML, et al. Cancer screening among Korean Americans. Cancer Pract 2001;9(3):134-140.

39. MacDonald DJ, Sarna L, Uman GC, Grant M, et al. Health beliefs of women with and without breast cancer seeking genetic cancer risk assessment. Cancer Nurs 2005; 28(5):372-379.
40. Lerman C, Daly M, Masny A, Balshem A. Attitudes about genetic testing for breastovarian cancer susceptibility. J Clin Oncol 1994;12:843-850.

41. Lerman C, Seay J, Balshem A, Audrain J. Interest in genetic testing among firstdegree relatives of breast cancer patients. Am J Med Genet 1995;57(3):385-392.

42. Julian-Reynier C, Eisinger F, Vennin P, Chabal F, et al. Attitudes towards cancer predictive testing and transmission of information to the family. J Med Genet 1996; 33(9):731-736.

43. MacDonald DJ, Sarna L, Uman GC, Grant M, et al. Cancer screening and risk reducing behaviors of women seeking genetic cancer risk assessment for breast and ovarian cancers. Oncol Nurs Forum 2006;33(2):E27-35.

44. Daly MB, Axilbund JE, Bryant E, Buys S, et al. Genetic/familial high-risk assessment: breast and ovarian. J Natl Compr Canc Netw 2006;4:156-176.

45. MacDonald DJ. Women's decisions regarding management of breast cancer risk. Medsurg Nurs 2002;11:183-186.

46. Manne S, Audrain J, Schwartz M, Main D, et al. Associations between relationship support and psychological reactions of participants and partners to BRCA1 and BRCA2 testing in a clinic-based sample. Ann Behav Med 2004;28(3):211-225.

47. Balmana J, Stoffel EM, Emmons KM, Garber JE, et al. Comparison of motivations and concerns for genetic testing in hereditary colorectal and breast cancer syndromes. J Med Genet 2004;41(4):e44.

48. Bonadona V, Saltel P, Desseigne F, Mignotte H, et al. Cancer patients who experienced diagnostic genetic testing for cancer susceptibility: reactions and behavior after the disclosure of a positive test result. Cancer Epidemiol Biomarkers Prev 2002; 11(1):97-104.

49. Smith KR, Zick CD, Mayer RN, Botkin JR. Voluntary disclosure of BRCAl mutation test results. Genet Test 2002;6(2):89-92. 